\title{
EVOLUÇÃO DO USO E COBERTURA DA TERRA E A FORMAÇÃO DE ASSENTAMENTOS HUMANOS EM ECOSSISTEMAS FRÁGEIS, ÁREAS PROTEGIDAS, DE RISCO OU DEGRADADAS: O CASO DA CIDADE DE MACAÉ (RJ-BRASIL)
}

\section{Evolution of land use and cover and the formation of human settlements in fragile ecosystems, protected, risk or degraded areas: Macaé's city case (Brazil)}

Carlos André Luz Jeronymo

Doutorando em Meio Ambiente - UERJ

carlosjeronymo@gmail.com

Tatiane dos Santos Alencar

Mestranda em Engenharia Ambiental - UERJ tatiane.santos.alencar@gmail.com

Elmo Rodrigues da Silva

Doutor em Saúde Pública - UERJ

elmorodrigues@yahoo.com.br

Fernanda Lerner

Mestre em Engenharia Ambiental - IFF

fernanda.lerner@hotmail.com

Artigo recebido em 15/09/2016 e aceito para publicação em 01/06/2017

DOI: $10.12957 /$ tamoios.2017.25599

\section{Resumo}

No final dos anos 1970, a descoberta do petróleo na Bacia de Campos trouxe a Petrobras e várias empresas ao município de Macaé, possibilitando o seu crescimento econômico. Em contrapartida, também provocou aumento populacional, ocupação desordenada do solo e impactos socioambientais. O objetivo deste trabalho foi analisar a evolução do uso/cobertura da terra no distrito sede de Macaé, com ênfase nos assentamentos humanos sobre ecossistemas frágeis, áreas protegidas, de risco ou degradadas. A abordagem da pesquisa foi qualitativa, realizada por meio de revisão bibliográfica e documental. Durante a urbanização do município, evidenciou-se avanços sobre os ecossistemas e áreas de risco, com deficiência ou inexistência de infraestrutura e serviços públicos. Observou-se um processo de segregação social e "gentrificação" nos espaços valorizados, similar ao ocorrido em outras cidades. A população de maior renda se instalou na área nobre e a de menor renda foi removida para áreas distantes da cidade. Além dos impactos sofridos, parte da população mais pobre permanece à margem do processo de produção e distribuição de riquezas geradas pela exploração petrolífera. $\mathrm{O}$ estudo sugere a elaboração de indicadores para avaliar políticas e ações voltadas para as populações vulneráveis residentes no município de Macaé e em áreas adjacentes.

Palavras-chave: uso e cobertura da terra; degradação ambiental; ocupação desordenada; assentamentos humanos; Macaé.

\begin{abstract}
In the end of the 1970 years, the discovery of the oil in Campos's Basin brought the Petrobras and several enterprises in Macaé city, making possible his economic growth. Nevertheless, it also provoked population increase, disordered occupation of the ground and impact socio-environmental. The objective of this work is to analyze the evolution of the use / covering of the land in Macaé city, with emphasis in the human registrations on fragile ecosystems, protected areas, of risk or degraded. The approach of the inquiry was qualitative, carried out through bibliographical and documentary revision. During the urbanization of the local authority, one showed advancements up on the ecosystems and areas of risk, with deficiency or non-existence of infrastructure and public utilities. A process of social segregation was pointed out and gentrification in the valued spaces, similarly to the occurred one in other cities. The population of bigger income was installed in the noble area and that of less income was moved for distant areas of the city. Besides the long-suffering impacts, part of the poorest population remains alongside the process of production and distribution of riches produced by the oil producing exploration. The study suggests the preparation of indicators to value policies and actions turned to the resident vulnerable populations in Macaé city and in adjacent areas.
\end{abstract}

Keywords: land use and cover; environmental degradation; disordered occupation; human settlements; Macaé city. 


\section{INTRODUÇÃO}

O Município de Macaé, também conhecido como a "Capital Nacional do Petróleo", se localiza na Região dos Lagos, norte fluminense do estado do Rio de Janeiro, Brasil. Ele-possui 1.216,846 km² de área, aproximadamente $22 \mathrm{~km}$ de linha de costa e praticamente todo seu território se localiza na bacia hidrográfica do rio Macaé, um dos principais cursos hídricos do estado do Rio de Janeiro, segundo a Secretaria de Estado do Ambiente (SEA, 2014).

Macaé também se encontra na "Bacia de Campos", maior reserva de petróleo offshore do país. A cidade de Macaé ou distrito sede $\left(1^{\circ}\right.$ distrito $)$ é o polo logístico no estado da Petrobras S/A (Petrobras) e de diversas multinacionais da cadeia do petróleo (PMM, 2012). Atualmente, a cidade é responsável por aproximadamente $78 \%$ da exploração nacional de petróleo e de seus derivados, conforme dados da Agência Nacional de Petróleo (ANP, 2014). Por essa razão, o Município integra a Organização dos Municípios Produtores de Petróleo (OMPETRO, 2016).

A base econômica de Macaé tornou-se a cadeia do petróleo a partir da instalação das unidades da Petrobras no distrito sede, no final da década de 1970. Desde então, diversas empresas de gestão da cadeia de suprimentos (suply chain management) se inseriram na cidade e região para atender a demanda da Petrobras e das multinacionais da cadeia do petróleo (RESSIGUIER, 2011).

Segundo Paganoto (2005), a oferta de empregos acima da média do estado, a alta arrecadação de Impostos Sobre Serviços de Qualquer Natureza (ISS) e os royalties do petróleo, serviram como atrativos na década de 1980, para diversos imigrantes, que buscavam a promessa de emprego. Todavia, esses empregos, em sua maioria, exigiam alta especialização, o que a maior parte dos imigrantes não possuía. Com isso, aqueles indivíduos não selecionados pela cadeia do petróleo foram absorvidos, a salários mais baixos (subempregos), pelo comércio local ou pela administração direta e indireta da Prefeitura, enquanto outros passaram a viver na informalidade. Houve o aumento no número de indigentes e miseráveis no Município, principalmente após a década de 1990 (AZEVEDO, 2011; RESSIGUIER, 2011).

Para Azevedo (2001), Ressiguier (2011) e Togeiro (2008), muitos dos problemas sociais enfrentados pelo Município são consequências das políticas públicas de gestão do território, ambiente, habitação, assistência social e educação, que até os anos 2000 eram inexistentes ou não atendiam de forma plena a demanda da cidade. Assim, a ausência ou deficiência dessas políticas provocaram uma ocupação desordenada no território da cidade, muitas vezes com a carência de infraestrutura urbana ${ }^{1}$ e de serviços públicos $^{2}$ (AZEVEDO, 2011; RESSIGUIER, 2011; TOGEIRO, 2008).

Mediante estas considerações indaga-se como se deu a mudança no uso e cobertura da terra na cidade de Macaé desde a emancipação do Município até os dias atuais. Acredita-se que esse processo se deu, e ainda se dá em grande parte, em áreas de risco (sujeitas à inundação, deslizamento, desmoronamento, contaminação, explosão), ecossistemas frágeis (restingas, brejos, mangues, campos alagados), áreas protegidas (Áreas de Preservação Permanente - APPs, Unidades de Conservação da Natureza UCs, Áreas Militares) e degradadas (por contaminação da água e solo, erosão acelerada, aterramento de áreas úmidas e corpos hídricos), sem a devida infraestrutura urbana e de serviços públicos. A premissa se baseia nas investigações de Tougeiro (2008) e Ressiguier (2011) que evidenciaram a existência de assentamentos humanos sobre esse tipo de área na cidade de Macaé e em Azevedo (2011) que investigou as condições deficientes de oferecimento de serviços públicos na cidade. 
Reconhecer a relação entre o processo histórico de uso e cobertura da terra na cidade de Macaé e a distribuição desigual dos riscos e perigos (e, consequentemente, de maior vulnerabilidade a estes riscos em determinados segmentos sociais), pode subsidiar ou direcionar políticas públicas, bem como evidenciar processos de vulnerabilidade que deverão ser sanados ou reavaliados.

O objetivo deste trabalho foi investigar os aspectos e/ou processos da evolução do uso e cobertura da terra na cidade de Macaé. Os objetivos específicos foram: (i) resgatar os aspectos históricos do processo de uso e cobertura da terra na cidade, desde a emancipação do Município até o período atual (2016); (ii) pesquisar como se deu a ocupação humana em ecossistemas frágeis, áreas protegidas, degradadas e de risco na cidade; e (iii) levantar a condição da infraestrutura urbana e de serviços públicos nos assentamentos humanos instalados nessas localidades.

No tocante à metodologia, o estudo possui uma abordagem qualitativa. Os procedimentos metodológicos executados neste trabalho envolveram o método hipotético-dedutivo e a pesquisa exploratória de gabinete, por meio de revisão de literatura e pesquisa documental. O recorte específico deste artigo buscou construir o cenário da evolução do uso e cobertura da terra da cidade de Macaé. Para isso foram consultados dados referentes ao Município de Macaé, por meio de softwares de busca on-line, textos acadêmicos, notícias de jornais, documentos e fontes oficiais.

\section{EVOLUÇÃO HISTÓRICA E RECENTE DO USO E COBERTURA DA TERRA DE MACAÉ}

\section{Da emancipação à Princesinha do Atlântico}

A ocupação do território de Macaé se deu em função das condições geográficas e da posição estratégica da sua sede, localizada em uma posição central e costeira, entre a capital do estado do Rio de Janeiro e o Município de Campos dos Goytacazes. O território do Município originalmente pertencia a Cabo Frio e Campos dos Goytacazes. Em 1813, a então "Macahé" se emancipou e, com isso, alcançou o status de Vila de São João de Macahé. No ano de 1846, o $1^{\circ}$ distrito (sede) foi reconhecido como cidade e o rio Miquié passou a ter seu nome Macaé (PMM, 2012; SOFFIATI, 2010).

A Figura 1 mostra a localização do Município de Macaé no Brasil e no Rio de Janeiro.

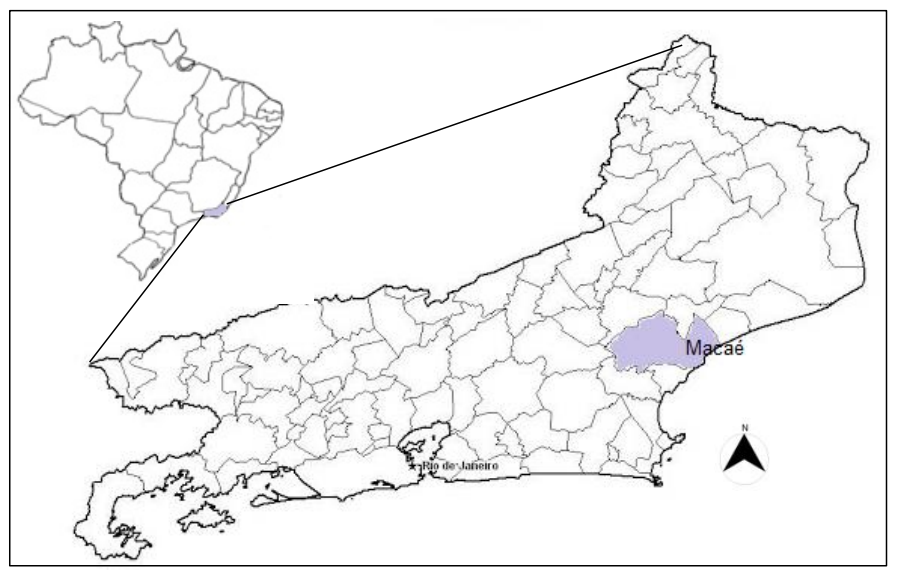

FIGURA 1- Localização do Município de Macaé no Brasil e no Rio de Janeiro. Fonte: Elaborado pelos autores em 2016. 
As primeiras edificações da Vila de São João de Macahé se situavam na região estuarina protegida na foz do rio Miquié e a oito quilômetros do Arquipélago de Santana (St. Ana). Nas décadas vindouras, do século XIX, a malha urbana se manteve na região central do distrito sede. Os motivos dessa localização foram: à proximidade ao rio Macaé, sua foz e o mar; a navegabilidade desse rio; as atividades pesqueiras no rio e no mar; e o pequeno cais de porto na foz do rio, onde eram efetuadas trocas comerciais (PMM, 2012; SOFFIATI, 2010).

No decorrer do século XIX, as atividades econômicas de Macaé se baseavam nos ciclos desenvolvidos na Mata Atlântica (extração de madeira e plantio de cana-deaçúcar no baixo curso da bacia hidrográfica do rio Macaé, plantio de café no alto curso e criação de gado na região do alto e médio curso) ${ }^{3}$ (PMM, 2012; SOFFIATI, 2010).

No final do século XIX, Macaé era eminentemente agrícola. Neste período, o Imperador Dom Pedro II decidiu construir um canal artificial, com mão de obra escrava, que conectaria Campos dos Goytacazes à cidade de Macaé. O motivo era a posição estratégica de Macaé para o escoamento da produção canavieira da região norte fluminense. O escoamento dessa produção para capital era efetuada por meio do porto, localizado na enseada protegida das praias das Conchas ${ }^{4}$ e Imbetiba. Ainda, o canal tinha como função promover a drenagem de áreas úmidas na região (PMM, 2012; SOFFIATI, 2010).

O canal foi construído entre 1845 e 1862, mas seu uso como forma de escoamento durou pouco tempo, em virtude da implantação da Rede Ferroviária Federal Campos/RJ, no ano de 1874. Nesta ocasião, o Município sofreu um novo impulso econômico e o vetor de crescimento da cidade se prolongou da área central até os bairros Imbetiba e Praia Campista, local de construção do terminal ferroviário (PMM, 2012; SOFFIATI, 2010).

Na década de 1930, a crise do café promoveu um forte êxodo dos distritos rurais produtores de café da região serrana de Macaé, o que levou o Município a se tornar eminentemente ferroviário. Em 1943 foi inaugurada a Rodovia Amaral Peixoto (RJ106) que liga Niterói a Campos dos Goytacazes. Esta rodovia proporcionou um aumento no fluxo turístico para Região dos Lagos, pela facilidade e rapidez no acesso a região. A partir desse fato se despertou uma vocação turística em Macaé que injetou recursos e proporcionou a instalação de pequenas indústrias locais (PMM, 2012).

Destaca-se que a consolidação da rodovia estadual RJ-106 interrompeu a dinâmica das águas que escoavam para os ecossistemas costeiros, além de aterrar áreas úmidas, braços de lagoa, desde o bairro Imboacica até o Lagomar, os dois bairros extremos na linha da costa da cidade (SOFFIATI, 2010).

No ano de 1950, se materializou a comodidade da população macaense, que passou a dispor de energia elétrica, por meio da Usina Hidroelétrica de Macabú (MACAÉ, 2010 a). O volume de água suficiente para funcionamento da Usina hidrelétrica de Macabú só foi possível mediante a transposição do Rio Macabú para o rio São Pedro, afluente do Macaé. As águas do rio Macabú originalmente contribuíam para a bacia hidrográfica da Lagoa Feia. Desde a transposição elas contribuem, em volume, para a bacia do rio Macaé (FREITAS et al., 2014).

A partir da década de 1960 o extinto Departamento de Obras e Saneamento (DNOS) iniciou uma série de obras de abertura de canais artificiais e retilinizações de cursos hídricos naturais, na bacia hidrográfica do rio Macaé. As obras do DNOS foram executadas no rio Macaé do fim do seu médio curso até a sua foz. O órgão também retilinizou ${ }^{5}$ diversos afluentes desta bacia hidrográfica neste mesmo trecho e escavou diversos canais artificiais de drenagem. O objetivo dessas obras era drenar as áreas úmidas na região do médio e baixo curso da bacia hidrográfica, a fim de diminuir os 
vetores de doenças de veiculação hídrica, aumentar as áreas de pastoreio e agricultáveis. Todavia, essas obras mudaram a configuração do território e ambiente macaense e, com isso, também possibilitou a ocupação de áreas ecologicamente sensíveis, antes inviáveis a ocupação humana, na região do baixo curso e foz do Macaé (SOFFIATI, 2010).

O rio Macaé e seus afluentes passaram de rios sinuosos a retilíneos ${ }^{6}$. Houve um aumento da vazão de suas águas, o dessecamento de uma vasta área alagada e alagável, além da substituição de ecossistemas nativos (campos alagados, brejos e mangues) por áreas de agropecuária. Como aspectos e impactos negativos dessas obras do DNOS têmse: destruição de nichos ecológicos, aumento da turbidez da água, assoreamento do rio, aumento da salinidade das águas e aumento da sedimentação do manguezal localizado na foz do rio (PMM, 2012; SOFFIATI, 2010).

Alguns trechos do baixo curso da bacia hidrográfica do rio Macaé se localizam abaixo do nível médio do mar. Durante a maré de sizígia alta ocorrem inundações naturais em diversas localidades, além do aumento da língua salina e da vazão reversa em pequenos cursos hídricos próximos a foz do rio. Este evento se tornou mais intenso devido as alterações no ciclo hidrológico provocadas pelas retilinizações e canalizações (SOFFIATI, 2010).

Ainda, as escavações do DNOS, à cerca de $2 \mathrm{~km}$ da foz do Macaé, formaram três ilhas artificiais fluviais: Ilha Colônia Leocádia (Leocádia), a Ilha da Caieira (Caieira) e uma sem identificação específica, conforme a literatura consultada. A maior ilha denominada Leocádia se formou entre a retilinização do rio Macaé e seu curso natural. A ilha sem identificação específica se formou acima da Leocádia. A Ilha da Caieira se originou entre a foz natural do Canal Jurumirim ${ }^{7}$, (hoje um braço morto ${ }^{8}$ ), o canal Campos Macaé (que passou a receber as águas do Jurumirim) e a retilinização do Macaé (PMM, 1956; 1966; 1976).

As obras do DNOS, a construção da rodovia Amaral Peixoto e da Usina Hidrelétrica de Macabú provocaram outro grande movimento interno de migração no Município, do campo para cidade, após o fim de suas obras até a década de 1970 (MACAÉ, 2010 a).

Na década de 1970 houve a crise do setor sucroalcooleiro e, por isso, diversos Municípios do Norte Fluminense produtores de cana, açúcar e álcool entraram em uma profunda crise econômica. No entanto, o Município de Macaé experimentou um grande crescimento econômico advindo do início da exploração petrolífera na Bacia de Campos (PMM, 2012; RESSIGUIER, 2011).

\section{DE PRINCESINHA DO ATLÂNTICO À CAPITAL NACIONAL DO PETRÓLEO}

O Município de Macaé, assim como outros Municípios do Brasil, foi influenciado pela política do progresso a qualquer custo e do crescimento econômico acelerado, típicos do período militar. Neste caso, as políticas públicas progressistas do governo militar e, posteriormente, as desenvolvimentistas do governo democrático, tinham como objetivo diminuir a dependência do país à importação de petróleo, por meio, do aparelhamento da Petrobras e do incremento do seu escopo de atividades (RESSIGUIER, 2011).

Dentro deste projeto, a Bacia de Campos era fundamental para reverter o quadro econômico do país. Macaé, dentre os Municípios do norte fluminense, foi escolhido para ser a sede logística on shore da cadeia do petróleo no estado do Rio de Janeiro. A escolha se pautou tanto na sua posição estratégica em relação à Bacia de Campos e a capital do estado, quanto pelo seu território possuir características geográficas e 
recursos naturais fundamentais à logística da cadeia petrolífera. Dentre estas características pode-se citar a enseada semi-protegida das Conchas e Imbetiba, onde foi instalado um porto para a cadeia de suprimentos (supply chain) e a água do rio Macaé ${ }^{9}$, que abastece boa parte das unidades on shore e off shore da Petrobras na Bacia de Campos (RESSIGUIER, 2011; SEA, 2014).

O final da década de 1970 marcou a história do Município de Macaé. A cidade com ar interiorano, antes conhecida como "Princesinha do Atlântico", sofreu profundas modificações econômicas, estruturais, culturais, territoriais e ambientais, em função da instalação das unidades da Petrobras e pelas políticas públicas nacionais e locais. Antes o Município era eminentemente agrícola, principalmente voltado à agroindústria açucareira. Neste momento, ele passou a ter sua economia focada na cadeia produtiva do petróleo (extração, produção e logística) (PMM, 2012; RESSIGUIER, 2011; SOFFIATI, 2010).

As obras de implantação das unidades da Petrobras, no final da década de 1970, instigaram milhares de pessoas ${ }^{10}$ a migrar para cidade de Macaé em busca de emprego especializado e não-especializado. Soffiati (2010) e Ressiguier (2011) narram que estas unidades cooptaram para o Município inúmeras empresas multinacionais e prestadoras de serviços da cadeia do petróleo, nas décadas de 1980 e 1990. Tais empresas, segundo os autores, geraram empregos diretos e indiretos, atraindo mais pessoas para cidade. Ainda, a abertura do mercado de exploração do petróleo no país, no final da década de 1990, provocou outro "boom" do número de empresas multinacionais e prestadoras de serviço na cidade. Consequentemente, houve outro aumento na oferta de empregos e arrecadação de impostos, principalmente os royalties e o ISS.

Por esta razão, Macaé experimentou um rápido crescimento econômico em menos de 30 anos. Nas décadas de 1980 e 1990 os royalties e ISS não eram tão altos quanto após a abertura do mercado, mas mesmo assim eles geraram uma receita maior que a média do estado do Rio de Janeiro e dos demais Municípios do país. Nas décadas de 1990 e 2000, o Produto Interno Bruto (PIB) do Município era um dos mais altos do Brasil e, por isso, Macaé foi considerada o "Eldorado do Petróleo". Como consequência, diversos migrantes de todo estado, país e mundo vieram para Macaé em busca de oportunidades (PAGANOTO, 2005; RESSIGUIER, 2011).

O Censo Demográfico do IBGE (2010, dados históricos de 1970-2010), mostra que em 1970, a população urbana do Município de Macaé ${ }^{11}$ era 39.802 habitantes e a rural era de 25.516 habitantes. No ano de 1990, sua população urbana passou a 89.336 habitantes, com um crescimento de $224 \%$, enquanto a população rural reduziu para 11.660 habitantes, uma redução de 45\%, em relação a 1970. No último censo, em 2010, o Município contabilizava 202.850 habitantes urbanos, um incremento de $227 \% \mathrm{em}$ relação a 1990 e de 509\% em relação a 1970. A população rural nesse ano contabilizava 3.860 habitantes, o que representa um decréscimo de 33\% em relação a 1990.

Assim percebe-se que a escolha da cidade de Macaé como sede logística on-shore e off-shore da Petrobras no estado mudou drasticamente a demografia do Município de Macaé, principalmente em sua sede. Diante disto, na década de 2000, Piquet (2003) relata que a Prefeitura intitulou a cidade como a "Capital Nacional do Petróleo" e as decisões tomadas pelos gestores públicos municipais passaram a ter a justificativa de atender o desenvolvimento econômico nacional e os interesses na exploração do petróleo e seus derivados. 


\section{EXPANSÃO DA MALHA URBANA DA CIDADE DE MACAÉ: DÉCADA DE 1970 A ATUAL}

Segundo Baruqui (2004), até a década de 1970 os vetores de crescimento da malha urbana da cidade de Macaé se concentravam no chamado centro histórico ou centro da cidade e seu prolongamento até a Imbetiba e Praia Campista. A partir da instalação das unidades da Petrobras eles passam a seguir três vetores: (i) nordeste, em direção ao Terminal Terrestre de Processamento e Distribuição de Gás de Cabiúnas (TECAB), no bairro Cabiúnas; (ii) sudoeste, em direção ao Parque de Tubos, no bairro Imboacica; e (ii) oeste em direção a BR-101, entrada principal da cidade. A Figura 2 mostra os bairros da cidade de Macaé com a localização das unidades da Petrobras.

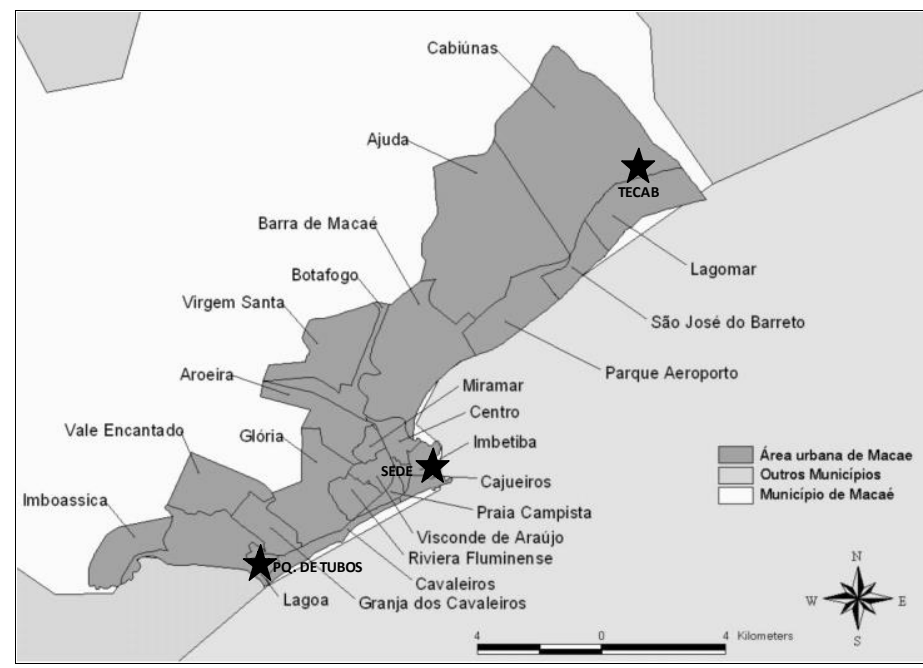

FIGURA 2: Ilustração dos bairros e unidades da Petrobras na cidade de Macaé (sede). Adaptado de Associação Brasileira de Estudos Populacionais - ABEP (2007) pelos autores, em 2016.

Ressiguier (2011) relata que no momento da instalação das unidades da Petrobras na cidade, não existiam políticas públicas municipais de gestão do território, ambiente e habitação. Por esta razão, as próprias unidades da empresa serviram como vetores de crescimento da malha urbana da cidade. Como consequência, residências, multinacionais e empresas prestadoras de serviços se instalaram de forma desordenada pelo território.

Soffiati (2010) mostra que os trabalhadores demitidos ao fim das obras da Petrobras e das multinacionais, na década de 1980, permaneceram nos arredores de onde trabalharam, com intuito de serem reintegrados no mercado de trabalho. Segundo o autor, muitos deles, por não possuírem poder aquisitivo, construíram suas moradias em praias rejeitadas pela classe econômica média e alta. A partir daí se formaram diversos assentamentos humanos de classe econômica baixa na cidade, carentes em infraestrutura urbana e serviços públicos.

Segundo Ressiguier (2011), a formação destes assentamentos humanos na cidade também se deu pelo crescimento populacional e estrutural de Macaé, nas décadas de 1980 e 1990. O autor mostra que este crescimento não foi acompanhado inicialmente por nenhum planejamento de infraestrutura urbana e de serviços públicos. Após a elaboração das políticas públicas de gestão de território, ambiente, habitação e proteção social na década de 2000-2010 não houve ações suficientes para atender a demanda popular $^{12}$. Por isso, Macaé passou a ter sérios problemas urbano-sociais, como o adensamento da ocupação do solo na área urbana da cidade, caos no sistema viário, 
atendimento precário nas áreas de saúde, saneamento, educação e o agravamento dos índices de poluição.

Dentre os assentamentos humanos de Macaé, cabe destacar a evolução do uso e cobertura da terra por alguns deles, em virtude das transformações no território e ambiente provocados pelas suas instalações e ocupações, ao longo das décadas de 19702000.

A configuração da drenagem e a dinâmica das águas no distrito sede de Macaé foi totalmente modificada em função da escavação de canais artificiais de drenagem e retilinizações de cursos hídricos. Presume-se que este seja um dos motivos dos problemas de inundações frequentes na cidade. Não existem cartas topográficas anteriores a essas retilinizações e algumas das ortofotos históricas não abrangem período anterior as obras. A reconstrução da trajetória das águas no distrito sede se deu por meio da análise das fotografias aéreas e ortofotos existentes e da história oral. Muitos cursos hídricos considerados canais artificiais pela população e pelo poder público são na verdade cursos hídricos naturais retilinizados, dentre eles o Córrego do Capote, Córrego do Morro e Córrego Jurumirim (JERONYMO et al., 2016).

No final da década de 1970 foi implantado um loteamento de alto poder aquisitivo na ilha da Caieira (formada pela retilinização do rio Macaé, já citada anteriormente). A ilha fluvial artificial possuía um remanescente de manguezal, mas com a instalação deste loteamento as árvores de mangue foram quase inteiramente suprimidas e a área úmida aterrada. Em 2016, a ilha ainda possuía um pequeno fragmento de manguezal, que foi doado em caráter permanente ao Instituto Nacional de Colonização e Reforma Agrária - INCRA (SOFFIATI, 2010). Ressiguier (2011) evidencia que tanto o loteamento quanto a doação são ilegais, pois, a área em questão, além de ser APP é de propriedade da União e da Marinha. Mesmo assim, o projeto do loteamento foi aprovado e regularizado pelo poder público.

Ainda, se consolidou na década de 1970, o bairro de classe econômica baixa Aroeira. A implantação da Aroeira se iniciou durante a criação da cidade por operários de construção civil. Suas edificações se consolidaram as margens da foz do córrego do Capote, na área conhecida popularmente como "triângulo", no centro-oeste da cidade (PMM, 2012). Em 2016, o bairro possuía diversas comunidades irregulares e em áreas de risco. Dentre as mais antigas estão o Morro do São Jorge e o Morro de Santana ${ }^{13}$, ambas com potencial risco de deslizamento. Parte do bairro foi regularizado pelo poder público, mesmo tendo sido edificado em áreas úmidas e na margem do córrego Capote (PMM, 2012; SOFFIATI, 2010).

O Capote é um afluente da bacia hidrográfica do Córrego do Morro que é uma sub-bacia do Macaé. Antes das obras de retilinização do DNOS, o Capote desaguava na foz de seu curso hídrico principal. Depois da sua retilinização, na década de 1950, ele foi canalizado até o canal das Malvinas e depois ao canal do Botafogo e, ambos os canais artificiais foram cavados para a drenagem de áreas úmidas. A foz da bacia hidrográfica do Morro era uma grande área úmida com manguezais. Após as obras de drenagem, suas águas passaram a verter para o rio Macaé por meio do canal das Malvinas, através de uma comporta manual (PMM, 1956; 1966; 1976).

Na década de 1980 se consolidou o assentamento Malvinas, em referência a guerra das Malvinas, entre a área úmida da foz do córrego do Morro e a margem direita do braço morto do rio Macaé. A partir de sua expansão desordenada, áreas de manguezal foram totalmente suprimidas e áreas úmidas da bacia hidrográfica do Morro foram aterradas para construção de edificações, sem nenhuma infraestrutura urbana ou serviços públicos. No final da década de 1980, a montante do braço morto do rio Macaé 
se formou a Malvinas II, que na década de 1990 se integrou a Malvinas (PMM, 2012; SOFFIATI, 2010).

A Figura 3 são ortofotos da área urbana e da foz do Rio Macaé datadas respectivamente de 1956, 1976 e 2001 e uma cena de satélite do Google Earth de 2016. Em 1956, o rio Macaé ainda não havia passado pela retilinização, mas a seu montante as obras já estavam sendo feitas. A noroeste da ortofoto se observa uma das curvas do antigo leito do rio Macaé e a presença de vegetação de mangue, ainda intacta. Na imagem da ortofoto de 1976 pode se observar o leito original do rio Macaé, a sua retilinização e a alteração da foz do Jurumirim para o canal Campos-Macaé com a localização das três ilhas: Leocádia, Caieira e a Ilha sem identificação. Pode-se observar o início da construção da segunda ponte sobre a foz do Rio Macaé, hoje usada para a o fluxo de automóveis, enquanto a primeira ponte foi reestruturada e serve para passagem de pedestres.

$\mathrm{Na}$ imagem de 1976, percebe-se um adensamento urbano entre o canal da Virgem Santa e o leito original do Rio Macaé, bairro designado como Malvinas. A área em questão era um manguezal utilizado como depósito de lixo e com a edificação de residências foi completamente aterrado. Na mesma imagem, percebe-se a formação de outros assentamentos humanos entre a porção direita da RJ-168 e as Malvinas. O assentamento que vai desde a porção de terra entre os canais das Malvinas e Botafogo até aquela acima deles, chama-se Novo Botafogo. Enquanto, o assentamento abaixo desses canais é conhecido como Botafogo. A ilha da Caieira, em 1976, já se encontrava ocupada, restando apenas uma pequena área de manguezal que permanece até o ano de 2016. Ao lado da ilha da Caieira se percebe o início da formação do assentamento Nova Brasília, sobre área de mangue e restinga, entre a ilha Caieira e o braço morto do Jurumirim.

Na margem esquerda do canal Campos-Macaé, também no final dos anos 1980, as ocupações da Nova Brasília se prolongaram até a margem direita do Campos-Macaé formando a Nova Holanda, uma grande área úmida e de manguezal que foi totalmente suprimida conforme as ocupações avançavam na região (PMM, 2012; SOFFIATI, 2010; TOUGEIRO, 2008). A ocupação da Nova Holanda pode ser vista na ortofoto do ano de 2001.

Na década de 1990, a cidade continuou se expandindo sobre áreas ambientalmente frágeis e de risco. Pode-se observar, nesse período, a consolidação da comunidade da Nova Holanda e o início de seu prolongamento até Nova Esperança, que podem ser vistos na ortofoto de 2001, a oeste. 


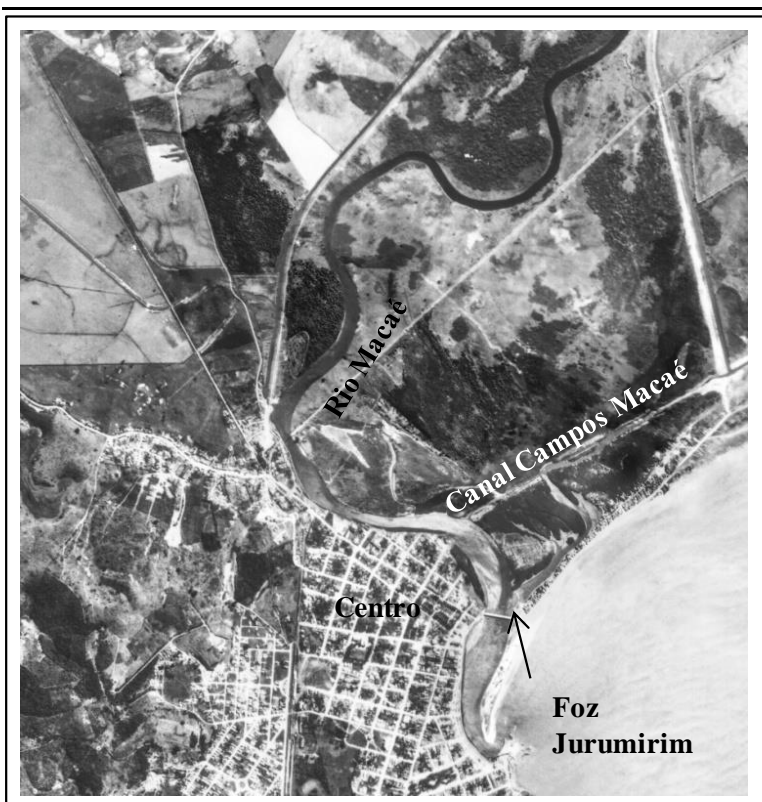

Ortofoto-1956

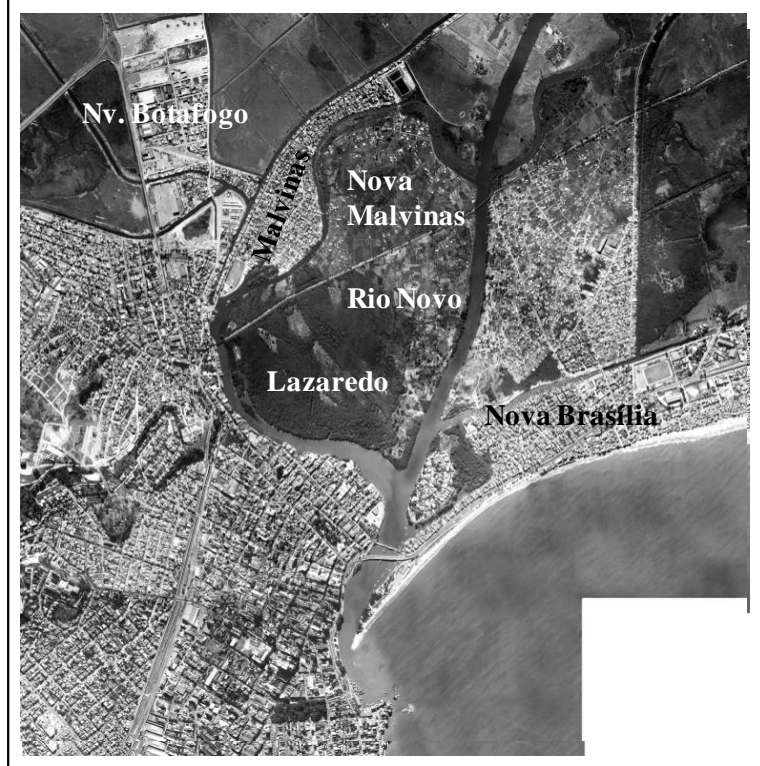

Ortofoto-2001

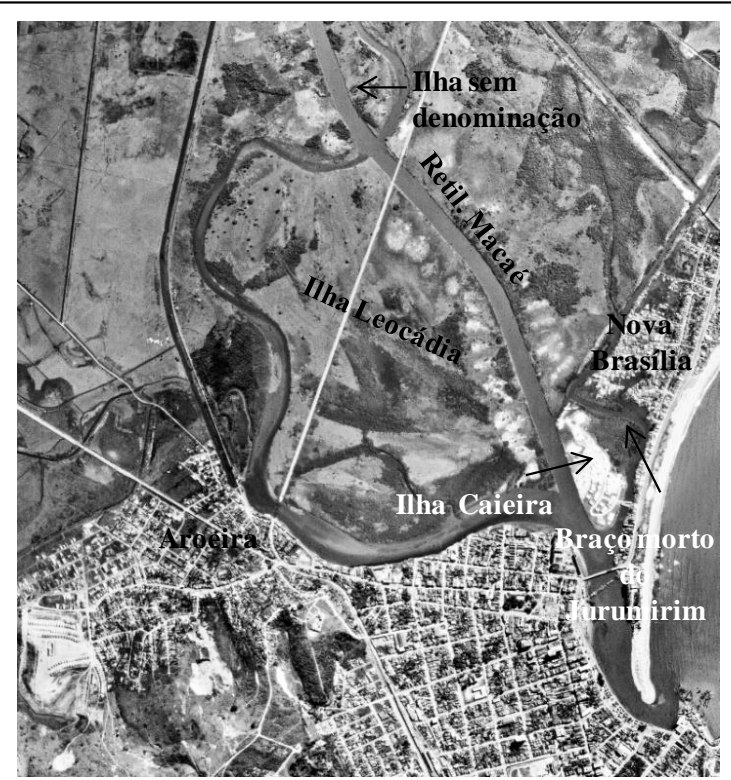

Ortofoto- 1976

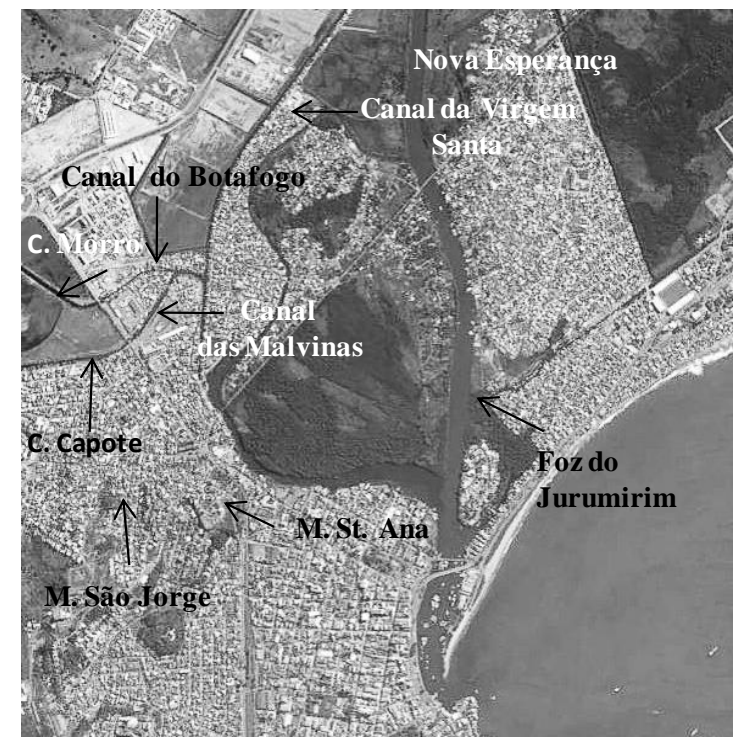

Imagem do Google Earth-2016

Figura 3: Evolução do Uso e Cobertura da Terra na foz do rio Macaé. Fonte: elaborado pelos autores, em 2016, com base em PMM (1956; 1976; 2001) e Google Earth (2016).

Também nessa década se dá o início da ocupação da Ilha Colônia Leocádia (TOUGEIRO, 2008). Nesta ilha se formaram duas comunidades: a Nova Malvinas e Rio Novo, respectivamente pelo prolongamento da Malvinas e Nova Holanda. A Ilha Colônia Leocádia, originalmente era coberta por mangues e áreas úmidas. Segundo Tougeiro (2008), o corte de mangue e o aterro das áreas úmidas da ilha foram feitos sem o controle do poder público. As duas comunidades carecem de infraestrutura urbana e serviços públicos e o acesso a localidade é feito através de pontes precárias de madeira, construídas a partir das Malvinas e Nova Holanda (PMM, 2012; SOFFIATI, 2010; TOUGEIRO, 2008).

$\mathrm{Na}$ ortofoto de 2001 é possível perceber o adensamento dos assentamentos humanos ocupados na década de 1980. A imagem de 2016 permite visualizar o atual contexto de ocupação no entorno da foz do rio Macaé. Observando a imagem, concluise que a ocupação das zonas centro-oeste e norte se deu, principalmente, sobre 
manguezais, áreas úmidas e restingas. O adensamento urbano foi provocado não só pela instalação de assentamentos humanos de baixo poder aquisitivo, mas também por empreendimentos industriais e moradias de alto poder aquisitivo, como a ilha da Caieira. Há de se observar também o adensamento das residências na Nova Malvinas, Nova Holanda, Nova Esperança e a invasão da Fazenda Piracema, acima da Nova Esperança.

Todavia, não foi apenas o entorno do rio Macaé que sofreu ocupações nas décadas de 1970, 1980 e 1990. A nordeste da foz do rio Macaé, na Barra de Macaé, se iniciaram as ocupações da praia e restinga da Fronteira e do Barreto. Lotes regulares localizados sobre áreas úmidas e de restinga foram invadidos e ocupados de forma irregular. Com isto, grande parte da vegetação foi suprimida e áreas úmidas e lagoas costeiras foram aterradas para construção de edificações, normalmente por populações de baixo poder aquisitivo, sem infraestrutura urbana e serviços públicos (PMM, 2012; SOFFIATI, 2010; TOUGEIRO, 2008).

Também se iniciou neste momento a ocupação desordenada do Lagomar, extremo nordeste da cidade. Inicialmente, esse loteamento era regular, de classe média, rural, com lotes de $5.000 \mathrm{~m}^{2}$, em área de restinga, áreas úmidas e lagoas costeiras. Posteriormente, a maioria dos seus lotes foram desmembrados, contrariando o tamanho mínimo regulamentado pela Prefeitura, ou invadidos por populações de baixo poder aquisitivo (TOUGEIRO, 2008).

A Figura 4 mostra a evolução do uso e cobertura da terra na zona norte da cidade de Macaé entre 1989 e 2016. 


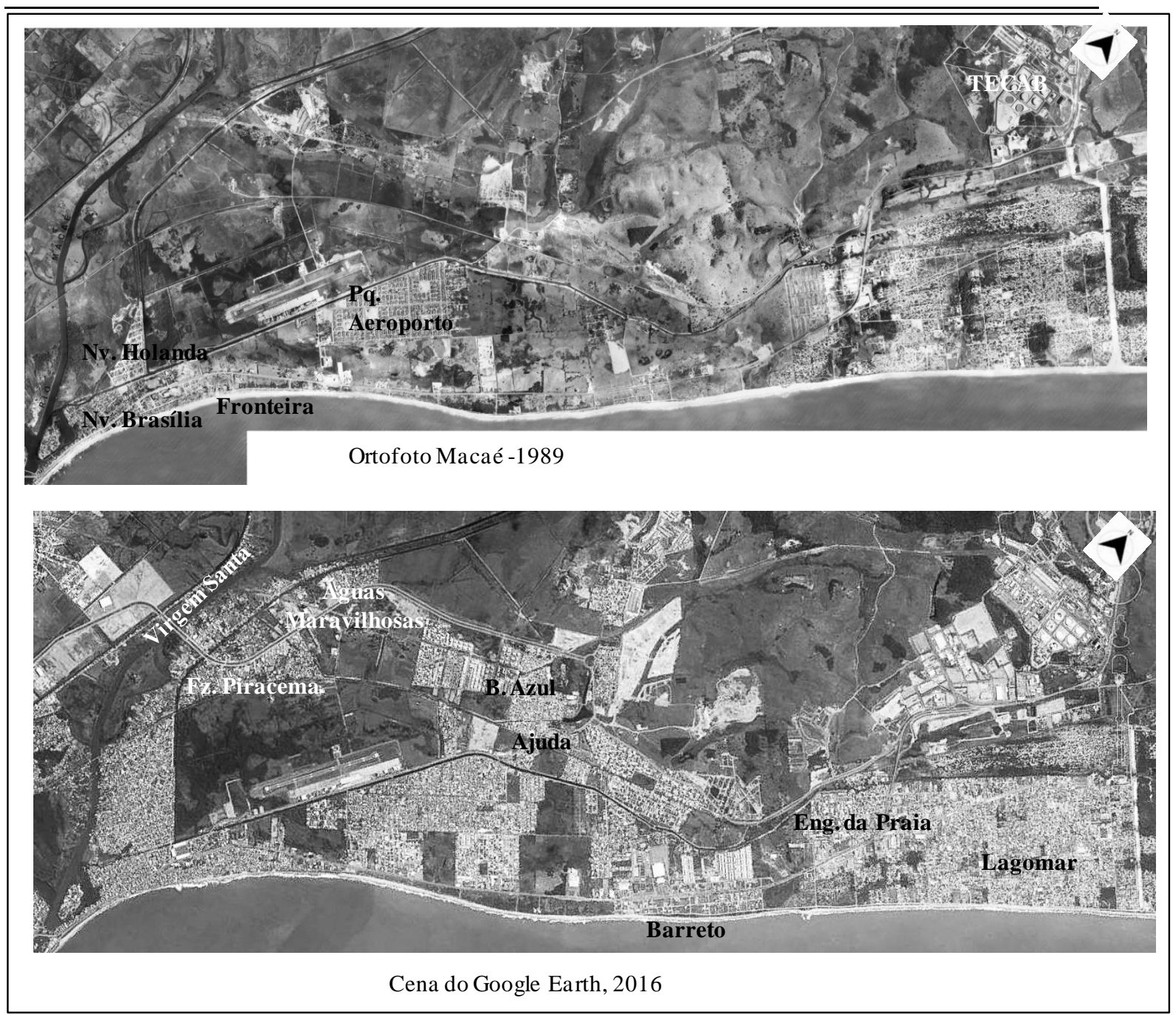

Figura 4: Evolução do uso e cobertura da terra na zona norte da cidade de Macaé. Fonte: Elaborado pelos autores, em 2016, com base em PMM (1989) e Google Earth (2016).

A grande expansão urbana da região nordeste de Macaé pode ser explicada por motivos econômicos. No final da década de 1990, houve a quebra do monopólio da Petrobras. A partir desse momento, Macaé teve um aumento vertiginoso na instalação de multinacionais e empresas de serviços da cadeia do petróleo, acompanhado por um crescimento de sua população. Nos anos 2000, a arrecadação de royalties e ISS aumentou de forma significativa, assim como o número de imigrantes brasileiros e estrangeiros (RESSIGUIER, 2011).

Nesse momento houve a formação de diversos assentamentos humanos de baixo e alto poder aquisitivo na cidade, além do adensamento dos já existentes. Dentre os de baixo poder aquisitivo, podemos citar o caso do Lagomar, que experimentou crescimento irregular e excessivo neste período. Como consequência do avanço das ocupações no bairro houve a supressão de uma grande parcela da restinga da formação de Jurubatiba ${ }^{14}$. Além disso, diversas áreas úmidas e lagoas costeiras foram aterradas para construção de moradias.

Segundo Ressiguier (2011), um dos principais motivos para instalação da maior parcela da população de baixa renda nas zonas centro-oeste e norte da cidade, foram os empregos oferecidos neste trecho da cidade. No vetor nordeste de Macaé se encontra o Polo Industrial de Cabiúnas, que ofereceu empregos de construção civil, assim como os de menor especialização da cadeia do petróleo. No tocante à região central, existia a 
oferta de subempregos, principalmente no comércio local. O autor ainda mostra que a especulação imobiliária na zona sul da cidade foi outro fator preponderante para ocupação de populações de baixa renda nas zonas centro-oeste e norte. Neste caso, os lotes eram mais acessíveis às populações de baixo poder aquisitivo ou os mesmos foram invadidos e ocupados, devido à carência de controle do poder público ou dos proprietários.

Enquanto isso, na zona sul, no final da década de 1970, se formou o bairro de Imboacica às margens do rio e da lagoa de Imboacica, limite com Município de Rio das Ostras. O entorno da Lagoa de Imboacica foi considerado Faixa Marginal de Proteção FMP (Lei Estadual nº650 de 1983), além de já ser APP (Lei Federal n 4771 de 1965, revogado pela Lei Federal $n^{0} 12.651$ de 2012). A lagoa e seu entorno no ano de 1987 também foram tombados como Área de Interesse Ambiental Estadual (Lei Estadual $\mathrm{n}^{\mathrm{o}}$ 1.130 de 1987). No final da década de 1970, pouco antes do entorno da Lagoa ser considerado FMP, se instalou na área o Parque de Tubos na unidade industrial da Petrobras.

Os impactos da instalação da Petrobras na década de 1970, o grande fluxo migratório da década de 1980 e a abertura para empresas estrangeiras também se fez sentir no sudoeste do Município. Devido à instalação desta unidade da Petrobras, o bairro de Imboacica antes rural, tornou-se industrial (RESSIGUER, 2011). Durante a evolução do uso e cobertura da terra desse bairro houve diversas alterações negativas do ambiente, regulares e irregulares, das quais exemplificam-se: (i) aterramento e manilhamento de cursos hídricos e nascentes; (ii) desmatamento; (iii) aterramento de áreas úmidas; (iv) desvio de curso e retilinização do rio Imboacica; (v) terraplanagens e nivelamento de terrenos; e, (vi) extração de saibro e brita (MACAÉ, 1976; 1989; 2001; 2010). Ao término da obra do Parque de Tubos, se formou nas proximidades um assentamento de baixo poder aquisitivo, sem nome definido na literatura, constituído principalmente pelos trabalhadores da obra (TOUGEIRO, 2008).

Nesse período, excetuando-se este assentamento, se desenvolveram diversos assentamentos de alto poder aquisitivo na zona sul da cidade ${ }^{15}$. Conforme aponta Ressiguier (2011), este processo de ocupação se deu pela proximidade do Parque de Tubos e da sede da Petrobras, localizada na praia Campista e por conta da beleza cênica das praias da zona sul e da Lagoa de Imboacica. No caso das duas unidades da Petrobras citadas, o autor relata que elas serviram como vetores de crescimento da malha urbana pelo fornecimento de empregos que exigiam especialização e ofereciam altos salários.

A margem da lagoa sofreu diversas modificações negativas advindas da instalação dos residenciais de alto poder aquisitivo e as restingas da praia Campista, dos Cavaleiros e do Pecado foram quase inteiramente suprimidas, mesmo sendo APPs. Nesse caso, tais assentamentos humanos foram regularizados pelo poder público apesar de se encontrarem em ecossistemas frágeis e áreas protegidas. Alguns exemplos são: os condomínios Mirante da Lagoa e os loteamentos Vivendas da Lagoa, Fazenda Mutum, Jardim Guanabara e Cavaleiros ${ }^{16}$. A Figura 5 mostra a evolução do uso e cobertura da terra em torno da Lagoa de Imboacica entre 1976 e 1989. 

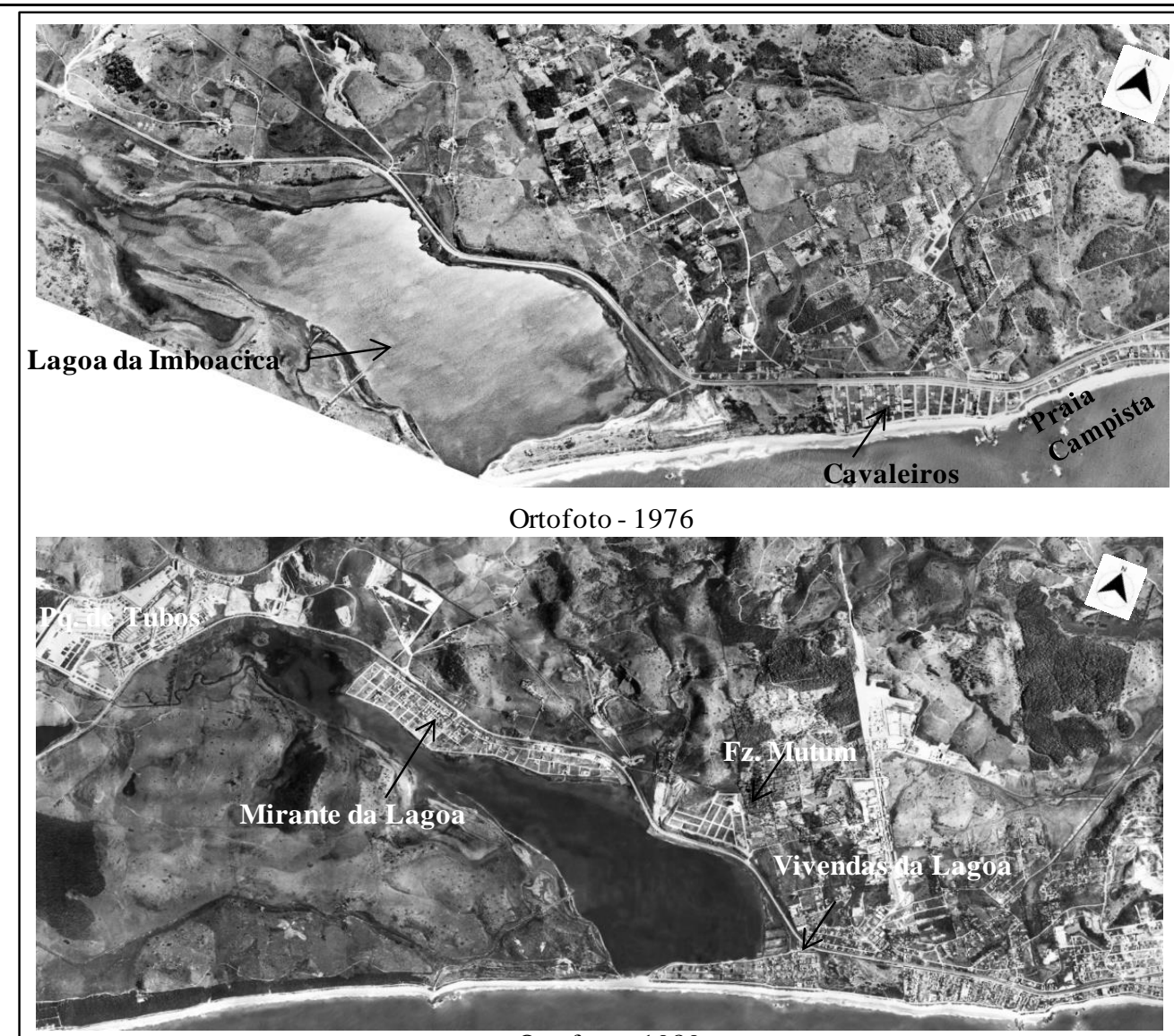

Ortofoto - 1989

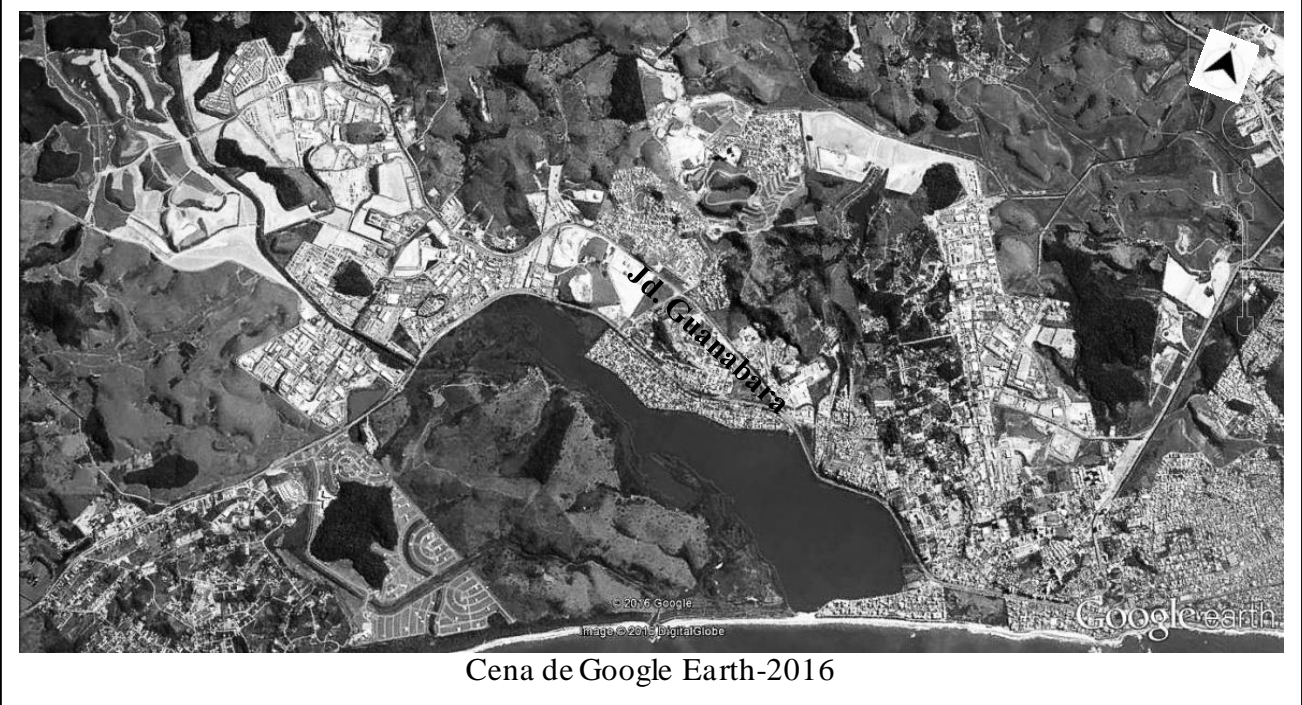

Figura 5: Entorno da Lagoa de Imboacica entre 1976 e 1989. Fonte: elaborado pelos autores, em 2016, com base em PMM (1976; 1989) e Google Earth (2016).

A análise da evolução do uso e cobertura da terra na cidade de Macaé revelou uma tendência na formação de diversos assentamentos humanos de forma desordenada e degradadora na cidade. Desta forma, foi feito um levantamento de cada assentamento humano localizado em ecossistemas frágeis, áreas protegidas, com risco ou degradadas para complementar esse estudo. O Quadro 1 sistematiza os resultados desse levantamento e traz uma caracterização destes assentamentos humanos, com dados sobre: a regularidade dos loteamentos ${ }^{17}$, renda média da população ${ }^{18}$, período do 
processo de ocupação, sua localização, infraestrutura urbana e o oferecimento de serviços públicos.

Os dados do Quadro 1 foram encontrados de forma dispersa e fragmentada em diversos documentos oficiais, dentre eles: (i) Anuário da Prefeitura Municipal de Macaé (PMM, 2012); (ii) Novo Código de Urbanismo (MACAÉ, 2010 b); (iii) Plano Local de Habitação de Interesse Social (MACAÉ, 2010 a); (iv) Plano Diretor do Município de Macaé (MACAÉ, 2006 a); (v) Política de Habitação de Interesse Social (MACAÉ, 2006 b); (vi) Código Municipal de Meio Ambiente (MACAÉ, 2001).

A leitura crítica destes documentos revelou que muitas das informações oficiais sobre a infraestrutura urbana e oferecimento de serviços públicos encontram-se com incongruências entre as diferentes bases de dados ou documentos utilizados pela própria Prefeitura. Dentre elas, pode-se citar infraestruturas urbanas e serviços dados como existentes em alguns locais, mas que ainda não possuem estes equipamentos públicos no momento de consulta a literatura, ou a inexistência ou deficiência de informações sobre alguns assentamentos humanos.

De forma complementar à leitura desses documentos, se analisou as ortofotos históricas digitais de Macaé (PMM, 1956; 1966; 1976; 1989; 2001; 2010) e cenas de satélites do Google Earth (2003-2016) para subsidiar o levantamento dos assentamentos humanos foco do estudo, principalmente na caracterização do ambiente nesses locais (área úmida, restinga, lagoas, entre outros). Além disso, foi feita uma pesquisa on line em jornais da região a fim de evidenciar a realidade de cada um destes lugares.

Para a pesquisa foram consultados os seguintes acervos: (Debate on line; Folha da Manhã on line; Jornal Expresso Regional on line; Jornal O Cidadão; lucianodiniz.com; PMM, notícias; PMM, Coleta de Lixo Residencial; PMM, Novo Aterro Sanitário). Literaturas acadêmicas também auxiliaram na caracterização desses sítios. Entre as leituras estão: (AZEVEDO, 2011; FERREIRA et al., 2010; MOLISANI et al., 2013 a; MOLISANI et al., 2013 b; RESSIGUIER, 2011; SOFFIATI, 2010; TOUGEIRO, 2008).

Observou-se nas análises que nem todos os assentamentos humanos na cidade possuem as informações disponíveis. A ausência de informações é mais frequente nos assentamentos humanos mais recentes (últimos 15 anos).

As informações foram dispostas conforme a localização geográfica dos assentamentos humanos na cidade de Macaé, primeiramente zona norte, depois a região central e, por último, a zona sul. 
Quadro 1: Caracterização dos assentamentos humanos na cidade de Macaé localizados em ecossistemas frágeis, áreas protegidas, com risco e degradadas

\begin{tabular}{|c|c|c|c|c|c|c|c|c|c|c|}
\hline $\begin{array}{l}\text { Assentamentos } \\
\text { humanos }\end{array}$ & Ocupação & Localização & Regularidade & Renda & $\begin{array}{c}\text { Infraestrutura } \\
\text { Urbana }\end{array}$ & $\begin{array}{l}\text { Serviços } \\
\text { públicos }\end{array}$ & $\begin{array}{l}\text { Ecossistema } \\
\text { frágil }\end{array}$ & $\begin{array}{c}\text { Área } \\
\text { Protegida }\end{array}$ & $\begin{array}{l}\text { Área com } \\
\text { risco }\end{array}$ & $\begin{array}{c}\text { Área } \\
\text { degradada }\end{array}$ \\
\hline Engenho da Praia & $\begin{array}{c}\text { Final da década } \\
\text { de } 1980\end{array}$ & Bairro Cabiúnas/NE & Irregular & Baixa & $\begin{array}{c}\text { INE (RA; RE; TE) } \\
\text { DEF (RS; PV; FL; } \\
\text { IP) }\end{array}$ & DEF & $\begin{array}{l}\mathrm{AU} ; \mathrm{RE} ; \mathrm{LC} ; \\
\mathrm{CH}\end{array}$ & $\begin{array}{l}\text { ZEIA-8; } \\
\text { APP; ZA }\end{array}$ & EX; CO; ID & $\mathrm{CO} ; \mathrm{AT}$ \\
\hline Balneário do Lagomar & $\begin{array}{l}\text { Final da década } \\
\text { de } 1980 / 2000\end{array}$ & $\begin{array}{l}\text { Balneário do } \\
\text { Lagomar/NE }\end{array}$ & $\begin{array}{l}\text { Regular/ } \\
\text { irregular }\end{array}$ & Baixa & $\begin{array}{l}\text { INE (RA; RE; TE) } \\
\text { DEF (RS; PV; FL; } \\
\text { IP) }\end{array}$ & DEF & AU; RE; LC & $\begin{array}{l}\text { APP; FS; } \\
\text { ZA }\end{array}$ & $\mathrm{EX} ; \mathrm{CO}$ & $\mathrm{CO} ; \mathrm{AT}$ \\
\hline $\begin{array}{c}\text { Complexo da Ajuda } \\
\text { (Ajuda de Baixo, } \\
\text { Planalto da Ajuda e } \\
\text { Gleba Nossa Senhora da } \\
\text { Ajuda) } \\
\end{array}$ & $\begin{array}{c}\text { Final da década } \\
\text { de } 1980 / \text { década } \\
\text { de } 1990\end{array}$ & $\begin{array}{c}\text { Nossa Senhora da } \\
\text { Ajuda/NO }\end{array}$ & $\begin{array}{l}\text { Regular/ } \\
\text { irregular }\end{array}$ & Baixa & $\begin{array}{l}\text { INE (RA; RE; TE) } \\
\text { DEF (RS; PV; FL; } \\
\text { IP) }\end{array}$ & DEF & $\mathrm{AU}$ & FS & $\begin{array}{l}\text { EX; CO; IN; } \\
\text { DE }\end{array}$ & $\mathrm{CO} ; \mathrm{AT}$ \\
\hline Aterrado do Imburo & Década de 2000 & $\begin{array}{c}\text { Nossa Senhora da } \\
\text { Ajuda/NO }\end{array}$ & Irregular & Baixa & $\begin{array}{l}\text { INE (RA; RE; TE; } \\
\text { RS; PV; IP); }\end{array}$ & INE & $\mathrm{AU}$ & - & IN & AT \\
\hline Bosque Azul & 2015 & $\begin{array}{c}\text { Nossa Senhora da } \\
\text { Ajuda/NO }\end{array}$ & $\begin{array}{c}\text { Loteamento } \\
\text { popular }\end{array}$ & Baixa & Em instalação & $\begin{array}{c}\text { Em } \\
\text { instalação }\end{array}$ & $\mathrm{AU}$ & - & IN & AT \\
\hline São José do Barreto & $\begin{array}{c}\text { Final da década } \\
\text { de } 1970 / \text { década } \\
\text { de } 1980\end{array}$ & $\begin{array}{l}\text { São José do } \\
\text { Barreto/NE }\end{array}$ & $\begin{array}{l}\text { Regular/ } \\
\text { irregular }\end{array}$ & Baixa & DEF & DEF & AU; RE; LC & ZEIA-7 & ID & AT \\
\hline Parque Aeroporto & $\begin{array}{c}\text { 1982/década de } \\
1990\end{array}$ & Parque Aeroporto/NO & $\begin{array}{l}\text { Regular/ } \\
\text { irregular }\end{array}$ & Baixa & INE (RE; TE) & DEF & AU; MG; & $\begin{array}{l}\text { ZEIA-6; } \\
\text { APP; ZA }\end{array}$ & $\begin{array}{c}\text { IN; CO; } \\
\text { INFRAERO }\end{array}$ & $\mathrm{CO}$ \\
\hline Nova Esperança & Década de 2000 & Barra de Macaé/N & Irregular & Baixa & $\begin{array}{c}\text { INE (RE; TE) } \\
\text { DEF (RA; RS; } \\
\text { PV; FL; IP) }\end{array}$ & DEF & AU; MG; & $\begin{array}{l}\text { APP; FS; } \\
\text { ZA; }\end{array}$ & IN; CO; LF & $\mathrm{CO} ; \mathrm{AT}$ \\
\hline Nova Malvinas & Década de 1990 & Barra de Macaé/N & Irregular & Baixa & INE & INE & $\mathrm{AU} ; \mathrm{MG}$ & $\begin{array}{l}\text { APP; FS; } \\
\text { UC; SPA }\end{array}$ & IN; CO; LF & $\mathrm{CO} ; \mathrm{AT}$ \\
\hline Rio Novo & Década de 1990 & Barra de Macaé/N & Irregular & Baixa & INE & INE & $\mathrm{AU} ; \mathrm{MG}$ & $\begin{array}{c}\text { APP; FS; } \\
\text { UC; ZEIA- } \\
4 \\
\end{array}$ & IN; CO; LF & $\mathrm{CO} ; \mathrm{AT}$ \\
\hline Ilha da Caieira & \begin{tabular}{|c|}
$\begin{array}{c}\text { Final da década } \\
\text { de } 1970\end{array}$ \\
\end{tabular} & Barra de Macaé/N & Regularizado & Alta & INE (RE; TE) & - & AU; MG & APP; ZA & IN; $\mathrm{CO}$ & $\mathrm{CO} ; \mathrm{AT}$ \\
\hline $\begin{array}{c}\text { Colônia de Pescadores } \\
\text { Z3 }\end{array}$ & $\begin{array}{l}\text { Ocupação } \\
\text { histórica }\end{array}$ & Barra de Macaé/N & Irregular & Baixa & $\begin{array}{l}\text { INE (RE; TE) } \\
\text { DEF (RA; RS) }\end{array}$ & DEF & $\mathrm{RE}$ & APP; ZA & IN; CO & $\mathrm{CO}$ \\
\hline
\end{tabular}




\begin{tabular}{|c|c|c|c|c|c|c|c|c|c|c|}
\hline Nova Brasília & $\begin{array}{l}\text { Final da década } \\
\text { de } 1960\end{array}$ & Barra de Macaé/N & Irregular & Baixa & $\begin{array}{l}\text { INE (RE; TE) } \\
\text { DEF (RA; RS) }\end{array}$ & DEF & AU; MG; RE & APP; ZA & IN; CO & $\mathrm{CO} ; \mathrm{AT}$ \\
\hline Nova Holanda & $\begin{array}{l}\text { Final da década } \\
\text { de } 1980\end{array}$ & Barra de Macaé/N & Irregular & Baixa & $\begin{array}{l}\text { INE (RE; TE) } \\
\text { DEF (RA; RS; } \\
\text { PV; FL; IP) }\end{array}$ & DEF & AU; MG & $\begin{array}{l}\text { APP; FS; } \\
\text { ZA }\end{array}$ & IN; CO; LF & $\mathrm{CO} ; \mathrm{AT}$ \\
\hline Fronteira & $\begin{array}{c}\text { Final da década } \\
\text { de } 1980\end{array}$ & Barra de Macaé/N & Irregular & Baixa & $\begin{array}{l}\text { INE (RE; TE) } \\
\text { DEF (RA; RS; } \\
\text { PV; FL; IP) }\end{array}$ & DEF & $\mathrm{RE}$ & APP & IN & ER \\
\hline Fazenda Piracema & Década de 2000 & Barra de Macaé/NO & Irregular & Baixa & INE & INE & $\mathrm{AU}$ & APP; FS & IN; CO; LF & $\mathrm{CO} ; \mathrm{AT}$ \\
\hline Águas Maravilhosas & Década de 2000 & Barra de Macaé/NO & Irregular & Baixa & INE & INE & $\mathrm{AU} ; \mathrm{CH}$ & APP & $\mathrm{IN} ; \mathrm{CO}$ & $\mathrm{CO} ; \mathrm{AT}$ \\
\hline Morro de Santana & Década de 1960 & Aroeira/CO & Irregular & Baixa & INE & DEF & MA & $\begin{array}{l}\text { APP; UC; } \\
\text { FS; SRU }\end{array}$ & DE; LF & ER \\
\hline Morro de São Jorge & Década de 1960 & Aroeira/CO & Irregular & Baixa & $\begin{array}{l}\text { INE (RE; TE) } \\
\text { DEF (RA; RS; } \\
\text { PV; FL; IP) }\end{array}$ & DEF & - & APP; SRU & DE; IN & MIN \\
\hline Botafogo & $\begin{array}{c}\text { 1950/década de } \\
1990\end{array}$ & Botafogo/CO & $\begin{array}{l}\text { Regular/ } \\
\text { Irregular }\end{array}$ & Baixa & $\begin{array}{c}\text { INE (RE; TE) } \\
\text { DEF (RA; RS; } \\
\text { PV; FL; IP) }\end{array}$ & DEF & MG; AU; & APP; & IN;CO; & $\mathrm{CO} ; \mathrm{AT}$ \\
\hline Novo Botafogo & Década de 2000 & Botafogo/CO & Irregular & Baixa & INE & INE & MG; AU; & $\begin{array}{l}\text { APP; SRU; } \\
\text { FS; }\end{array}$ & IN;CO; LT & $\mathrm{CO} ; \mathrm{AT}$ \\
\hline Malvinas & 1982 & Botafogo/CO & Irregular & Baixa & $\begin{array}{l}\text { INE (RE; TE) } \\
\text { DEF (PV) }\end{array}$ & DEF & $\begin{array}{l}\mathrm{MG} ; \mathrm{AU} ; \\
\mathrm{CH}\end{array}$ & APP; & IN; CO & $\mathrm{CO} ; \mathrm{AT}$ \\
\hline Morro do Lazaredo & $\begin{array}{l}\text { Ocupação } \\
\text { histórica }\end{array}$ & Botafogo/CO & Irregular & Baixa & $\begin{array}{l}\text { INE (RE; TE) } \\
\text { DEF (RS; IP) }\end{array}$ & DEF & - & $\begin{array}{l}\text { APP; FS; } \\
\text { SRU }\end{array}$ & IN; LT & CT; AT \\
\hline Canal da Virgem Santa & Década de 2000 & Virgem Santa/NO & Irregular & Baixa & INE & INE & $\mathrm{AU}$ & APP; SPA & IN & AT \\
\hline Morro de Santa Mônica & $\begin{array}{l}\text { - 1970/ década } \\
\text { de } 1970\end{array}$ & Miramar/ CO & $\begin{array}{l}\text { Regular/ } \\
\text { Irregular }\end{array}$ & Baixa & DEF & DEF & SI & SI & $\mathrm{DE}$ & SI \\
\hline $\begin{array}{c}\text { Igreja Nossa Senhora de } \\
\text { Fátima }\end{array}$ & Década de 1990 & Centro/Centro & Irregular & Baixa & SI & SI & - & SRU & IN & SI \\
\hline
\end{tabular}




\begin{tabular}{|c|c|c|c|c|c|c|c|c|c|c|}
\hline Roque Santeiro & $\begin{array}{c}\text { Final da década } \\
\text { de } 1970\end{array}$ & $\begin{array}{c}\text { Praia Campista, } \\
\text { Visconde de Araújo e } \\
\text { Cajueiros/Centro } \\
\end{array}$ & Irregular & Baixa & INE & INE & - & SRU; FS & IN; LF; CO & $\mathrm{CO}$ \\
\hline Morobá & $\begin{array}{l}\text { Final da década } \\
\text { de } 1970\end{array}$ & $\begin{array}{l}\text { Praia Campista, e } \\
\text { Cajueiros/Centro }\end{array}$ & Irregular & Baixa & $\begin{array}{l}\text { INE (RE; TE; RS; } \\
\text { PV; FL; IP) }\end{array}$ & INE & - & FS & IN; LF; CO & $\mathrm{CO} ; \mathrm{AT}$ \\
\hline Morro do Carvão & Década de 1950 & Cajueiros/Centro & Irregular & Baixa & INE & INE & - & FS & IN; LF & - \\
\hline Novo Horizonte & $\begin{array}{l}\text { Década de } \\
1980 / 1990\end{array}$ & $\begin{array}{l}\text { Riviera Fluminense/ } \\
\text { SO }\end{array}$ & Regular/Irregular & Baixa & DEF & DEF & $\mathrm{AU}$ & APP; SRU & IN & CT; AT \\
\hline Vale Encantado & $\begin{array}{l}\text { Década de } \\
1970 / 2000\end{array}$ & $\begin{array}{c}\text { Novo Cavaleiros, } \\
\text { Granja dos Cavaleiros } \\
\text { e Vale Encantado/SO }\end{array}$ & Regular/Irregular & Alta/Baixa & $\begin{array}{c}\text { INE (RA; RE; TE; } \\
\text { RS; PV; IP) } \\
\text { DEF (FL) }\end{array}$ & INE & $\begin{array}{l}\mathrm{AU} ; \mathrm{MA} ; \\
\mathrm{CH} ;\end{array}$ & APP; AIA; & IN & CT: AT \\
\hline Imboacica & $\begin{array}{l}\text { Final da década } \\
\text { de } 1970\end{array}$ & Imboacica/SO & Irregular & Baixa & $\begin{array}{c}\text { INE (RA; RE; TE; } \\
\text { RS; FL; IP) } \\
\text { DEF (PV) }\end{array}$ & INE & - & APP; SRU & IN; ID & - \\
\hline Mirante da Lagoa & $\begin{array}{c}\text { Final da década } \\
\text { de } 1970\end{array}$ & Lagoa/SO & Regularizado & Alta & - & - & $\mathrm{LC}$ & APP & IN & AT \\
\hline Vivendas da Lagoa & $\begin{array}{c}\text { Final da década } \\
\text { de } 1970\end{array}$ & Cavaleiros/SO & Regularizado & Alta & - & - & $\mathrm{RE}$ & APP & IN & AT \\
\hline Jardim Guanabara & Década de 1990 & Lagoa/SO & Regularizado & Alta & - & - & AU; LC & APP & IN & AT \\
\hline Fazenda Mutum & Década de 1990 & Lagoa/SO & Regularizado & Alta & - & - & AU; LC & APP & IN & $\mathrm{AT}$ \\
\hline Cavaleiros & Década de 1970 & Cavaleiros/SO & Regularizado & Alta & - & - & $\mathrm{RE}$ & APP & - & - \\
\hline Praia Campista & Década de 1970 & Cavaleiros/SO & Regularizado & Alta & - & - & $\mathrm{RE}$ & APP & - & - \\
\hline
\end{tabular}

Legenda: N: Norte; NE: Nordeste; NO: Noroeste; CO: Centro-oeste; SO: Sudoeste; Infraestrutura Urbana (INE - inexistente; DEF - deficiente, ou seja, é precária, sem regularidade ou não atende todo assentamento; RA- rede de abastecimento de água; RE - rede coletora de efluentes domésticos; TE - tratamento de efluentes domésticos; RS - coleta e disposição de resíduos sólidos; PV - pavimentação; FL - fornecimento de energia elétrica; IP - iluminação pública); Ecossistema frágil (AU - área úmida; RE restinga; LC - lagoa costeira; MA - Mata Atlântica; MG - manguezal; CH - curso hídrico; Área Protegida (ZEIA - Zona de Especial Interesse Ambiental; SRU - Setor de Requalificação Urbano-Ambiental; SPA - Setor de Preservação Ambiental; AIA - Área de Interesse Ambiental; APP - Área de Preservação Permanente; UC - Unidade de Conservação da Vida Silvestre; FS - faixa de servidão; ZA - Zona de Amortecimento); Área com risco (EX - explosão; CO - contaminação; IN - inundação; DE deslizamento ou desmoronamento; LF - linha férrea; LT - linha de transmissão de energia de alta tensão; ID: atividades industriais; INFRAERO - aeroporto de Macaé); Área degradada (CT - corte de morro; AT - aterramento de áreas úmidas ou corpos hídricos; ER - processo de erosão acelerada; CO - contaminação do solo ou água; MIN mineradora desativada); SI - sem informações encontradas. Fonte: elaborado pelos autores (2016) 
A partir do Quadro 1 pode-se observar que:

(i) existem 38 assentamentos humanos na cidade de Macaé instalados sobre ecossistemas frágeis, áreas protegidas, com risco ou degradadas, sendo 30 de baixo poder aquisitivo, um loteamento popular e sete de alto poder aquisitivo; (ii) os 30 assentamentos de baixo poder aquisitivo possuem infraestrutura urbana inexistentes ou deficientes, o loteamento popular encontra-se ainda em instalação dos equipamentos públicos e somente o loteamento da Ilha da Caieira (alto padrão) não possui rede coletora de efluentes domésticos e o tratamento desses efluentes; (iii) 30 assentamentos humanos encontram-se sobre ecossistemas frágeis, sendo que os sete de alto poder aquisitivo estão nesta situação; (iv) 23 desses assentamentos estão sobre áreas úmidas, oito em restinga e seis aterraram cursos hídricos e lagoas costeiras; (v) 35 assentamentos humanos estão sobre áreas protegidas e, dentre estes, todos os de alto poder aquisitivo estão nessa situação; (vi) 36 assentamentos humanos encontram-se em áreas com risco, dentre estes todos os de baixo poder aquisitivo; (vii) 32 assentamentos humanos estão sobre áreas degradadas, sendo que somente quatro dos assentamentos de baixo poder aquisitivo não se encontram nessa situação; (viii) seis assentamentos humanos de baixo poder aquisitivo foram considerados por este trabalho como os casos mais graves por não apresentarem infraestrutura urbana e serviços públicos e ainda se encontrarem instalados sobre ecossistemas frágeis, áreas protegidas, com risco e degradadas ao mesmo tempo, dentre eles: Nova Malvinas; Rio Novo; Fazenda Piracema; Águas Maravilhosas; Novo Botafogo; e a comunidade ao longo do Canal da Virgem Santa.

Em relação ao saneamento básico, os dados oficiais de Macaé mostram que o Município possui Estações de Tratamento de Efluentes (ETEs) e um aterro sanitário que atende toda a cidade desde 2008 (PMM, 2012), ou seja, o Município declara que sua sede possui saneamento básico em toda a cidade. Entretanto, essa informação é refutada por meio das reportagens consultadas, inclusive da própria Prefeitura, em uma gestão diferente da que elaborou os documentos. A coleta de disposição dos resíduos sólidos não abrange todos os assentamentos humanos e, em alguns, encontra-se deficiente. A ETE Centro, próxima ao Capote, está em construção e tem a expectativa de tratar a nível terciário os efluentes domésticos de 23 bairros. A ETE Lagomar está passando por obras para entrar em operação pela primeira vez e a ETE Aeroporto encontra-se abandonada.

Em 2015, somente a ETE Mutum, localizada próxima ao Jardim Guanabara, estava em funcionamento no distrito sede. Ela é administrada por uma concessionária e faz o tratamento dos efluentes domésticos a nível terciário ${ }^{19}$. Cabe observar que a rede coletora ainda não foi completamente instalada e o efluente tratado é lançado na Lagoa de Imboacica, corpo hídrico fechado. Assim, os efluentes domésticos em Macaé continuam, em geral, sendo dispostos em fossa-filtro-sumidouro, nos corpos hídricos ou diretamente nos solos (a céu aberto ou em fossas).

O fornecimento de água também não chega a todos os assentamentos humanos na cidade, principalmente nos da zona norte. Em alguns dos assentamentos, onde existe rede de distribuição de água potável, têm-se relatos de fornecimento deficiente.

A segregação residencial é o processo por meio do qual uma determinada população involuntariamente é forçada a se agrupar em uma dada área (MARCUSE, 2004). Essa segregação ocorre quando indivíduos de baixo poder aquisitivo não conseguem se instalar em áreas regularizadas, com oferta de infraestrutura e serviços públicos em função de não poderem adquirir os imóveis ou os lotes. Assim, essas pessoas acabam por ocupar ecossistemas frágeis, áreas protegidas, com risco ou isoladas. Desta forma, constata-se neste artigo uma nítida segregação residencial entre 
as zonas centro-oeste, norte e a zona sul de Macaé, o que corrobora as observações de Ressiguier (2011).

Outra questão envolve o loteamento popular Bosque Azul I. O programa Habitar Legal procurou projetar à instalação de habitações em terrenos urbanizados, com intuito de melhorar a qualidade de vida da população e facilitar o acesso a moradia digna. Dentre os projetos desse programa, o Bosque Azul (dividido em três fases: I, II e III) foi um dos principais. O objetivo do Bosque Azul era realocação de populações em áreas de risco e oferecimento de moradias populares pelo programa Minha Casa Minha Vida. No entanto, esse projeto não foi executado em 2006, quando estava previsto, e o Município continuou sem atender a demanda por moradias populares até 2015. Em 2016, o Bosque Azul I já possuía moradores instalados, porém os equipamentos públicos ainda estão em processo de instalação. Além disso, a área escolhida para edificação encontra-se em um espaço distante da região central no noroeste da cidade. Esta área também faz parte de uma grande área úmida da Bacia Hidrográfica do Córrego Jurumirim que sofre constantes inundações, ou seja, uma área de risco.

Segundo Marcuse (2004), a remoção de pessoas instaladas em ocupações irregulares e sua realocação em áreas distantes da sua localização original caracteriza o processo denominado de gentrificação. Além disso, esse processo se torna mais nítido nos casos das remoções para fins de preservação ambiental em assentamentos humanos próximos às áreas nobres da cidade, valorizadas ou em valorização, como Novo Horizonte, Imboacica, Nova Malvinas, Morro de Santana, Morro de São Jorge, Novo Botafogo e Rio Novo.

O contraste observado neste trabalho se dá no caso dos loteamentos de alto poder aquisitivo que foram regularizados e vêm recebendo infraestrutura urbana e serviços públicos, mesmo esses estando instalados em ecossistemas frágeis, áreas protegidas e com risco ou degradadas. Em momento algum, foram observados questionamentos quanto à demolição, remoção e realocação de populações nesses assentamentos humanos de alto poder aquisitivo para fins de preservação do ambiente, apesar deles também terem provocado, e ainda provocarem, processos de degradação ambiental. Este também foi observado por Tougeiro (2008) em alguns dos assentamentos humanos que foram destacados neste trabalho.

\section{CONSIDERAÇÕES FINAIS}

O processo histórico e recente de uso e cobertura da terra na cidade de Macaé se deu e ainda se dá, em grande parte, em áreas de risco (de inundação, deslizamento, desmoronamento, contaminação, explosão, atividades industriais, aeroporto, linha férrea e de transmissão de alta tensão), em ecossistemas frágeis (Mata Atlântica, restingas, áreas úmidas, mangues, cursos hídricos e lagoas costeiras), em áreas protegidas (APP; UC; Zona de Amortecimento; faixas de servidão; zonas e setores especiais ambientais) ou em áreas degradadas (por contaminação da água e solo, erosão acelerada, aterramento de áreas úmidas e corpos hídricos), com deficiência ou inexistência de infraestrutura urbana e de cobertura de serviços públicos.

No processo de ocupação da cidade de Macaé houve uma tendência para que eles fossem realizados nesses locais. Primeiro pelo estímulo provocado pela instalação das unidades da Petrobras e empresas de serviço da cadeia do petróleo nessas áreas e, posteriormente, pela deficiência no controle do poder público. Revelou-se que grande número de assentamentos humanos de baixo poder aquisitivo estão localizados em ecossistemas frágeis, áreas protegidas, de risco ou degradadas. 
Todavia, existem assentamentos humanos de alto poder aquisitivo nas mesmas condições de localização. O contraste se dá no tratamento do poder público ao regularizar os loteamentos de alto poder aquisitivo e de instalar neles infraestrutura urbana e serviços públicos. Contudo, nos assentamentos humanos de baixo poder aquisitivo há inexistência ou deficiências de serviços e infraestrutura nestes equipamentos públicos. A justificativa é que essas populações devem ser removidas e realocadas a fim de preservar o ambiente ou pela área possuir risco ambiental.

Ocorre, portanto, uma nítida segregação residencial que se consolidou entre as zonas centro-oeste, norte (baixo poder aquisitivo e carente de equipamentos públicos) e a zona sul (alto poder aquisitivo com infraestrutura urbana e serviços públicos de qualidade). O agravante é o diferencial no tratamento para com as populações de baixo poder aquisitivo durante as remoções e realocações para áreas distantes de suas moradias, principalmente em relação a grupos localizados em áreas nobres ou em valorização.

Tal questão se caracteriza como processo de gentrificação, como ocorre em outras cidades brasileiras. No caso da cidade de Macaé, essas populações estão sendo realocados em sua maior parte para o Bosque Azul, um loteamento popular ainda sem os equipamentos públicos devidamente instalados, uma área com risco de inundação e distante do centro urbano.

Considera-se que a formulação de políticas públicas e tomadas de decisão por meio de procedimentos tecnocráticos e, muitas vezes, movida por interesses corporativistas ou de setores influentes, quando embasados por estudos científicos tendenciosos, podem provocar ou acirrar os conflitos socioambientais e, consequentemente, intensificar os processos de vulnerabilidade (social, econômica, ambiental e socioambiental) de uma região, como evidenciou-se no município estudado.

Recomenda-se a realização de novos estudos que avaliem os impactos das políticas e das ações do poder público em relação à gestão dos territórios dos assentamentos humanos de baixo poder aquisitivo realizados no município de Macaé e áreas adjacentes.

\section{NOTAS}

1 - Rede de distribuição de água potável, rede coletora de efluentes, tratamento de efluentes, recolhimento e destinação ambientalmente adequada de resíduos, pavimentação, fornecimento de luz e iluminação pública.

2 - Saúde, segurança, educação, cultura, habitação, proteção social, acessibilidade e informação.

3 - Cabe salientar que a atividade de cultivo de cana-de-açúcar era promovida, em sua maior parte, em áreas que hoje fazem parte de outros municípios (Quissamã, Conceição de Macabú e Carapebus) (PMM, 2012).

4 - A praia das conchas era uma pequena enseada adjacente a Imbetiba. Ela foi aterrada durante a construção do porto da Petrobras. Sua antiga localização é a atual portaria da sede Imbetiba da empresa (MACAÉ, 2012).

5 - Retilinizações e canalizações de cursos hídricos foram estratégias desenvolvidas pela Alemanha no final do século XIX, que se mostraram equivocadas na década de 1960, devido aos seus diversos impactos negativos. Dessa forma, o Brasil promoveu obras de engenharia em um momento em que essas estratégias já se mostravam obsoletas. Enquanto isso, outros países estavam desenvolvendo projetos de renaturalização dos corpos hídricos, com intuito de reverter os impactos negativos provocados pelas retilinizações e canalizações (MACHADO et al., 2010). No caso de canalizações, ainda é comum observar no município a sua escavação, bem como aterro e manilhamento de corpos hídricos naturais (SEA, 2014).

6 - Muitos desses rios e córregos não são mais reconhecidos pela população como naturais. Atualmente, o senso comum é de que eles são canais artificiais de drenagem e não rios naturais-retilinizados, ou seja, protegidos por lei. 
7 - Em observação de campo, em outro trabalho realizado pelos autores, percebeu-se que o canal Jurumirim é o rio São Sebastião dos Quarenta. Ele passa a se chamar Jurumirim quando sai do território de Conceição de Macabú e entra no território de Macaé, na BR-101. Fato esse confirmado após uma consulta as cartas-topográficas do IBGE.

8 - No local pode ser observado que a foz do Jurumirim, agora um braço morto, está contaminado e a renovação de suas águas ocorre basicamente por influência da maré. Fato corroborado em Molisani et al. (2013 a; b). A Colônia de pescadores Z3 se localiza exatamente nesse trecho do curso hídrico e o braço morto serve de ponto de atracação dos barcos de pesca.

9 - A instalação do porto da Petrobras na enseada das Conchas e Imbetiba resultou no aterrramento e desaparecimento da praia das conchas.

10 - Os imigrantes vieram, principalmente, do estado do Rio de Janeiro, mas foram observadas significativas quantidades de representantes de todo o país e até mesmo de estrangeiros (RESSIGUIER, 2011).

11 - Nestes dados se incluem os dados referentes à Carapebus que se emancipou de Macaé em 1997.

12 - Macaé possuiu vilas operárias e residenciais produzidas pelos empreendedores e pelos próprios empregados, além da vila militar. Em 1982, o poder público promoveu um Conjunto Habitacional Popular chamado Parque Aeroporto, hoje um dos mais populosos do município. Em 1982, foram entregues 1.572 unidades residenciais, visando atender à demanda populacional de famílias de baixo poder aquisitivo. Após 1994, o bairro recebeu investimentos habitacionais particulares que criaram conjuntos habitacionais como a Vila Badejo (300 unidades), Dourado (52 unidades), Marlin (56 unidades), Linguado (54 unidades), Viola (52 unidades), Atum (54 unidades) e Namorado (58 unidades) (PLHIS, 2010).

13 - Ambas as comunidades datam do final da década de 1950, sendo o morro de São Jorge uma antiga pedreira abandonada.

14 - No entorno imediato do Bairro Lagomar se encontra o Parque Nacional da Restinga de Jurubatiba, criado em 1998 para conservar os resquícios de restingas e lagoas existentes na região Norte Fluminense (TOUGEIRO, 2008).

15 - O termo zona sul é utilizado na literatura consultada para descrever o trecho entre a sede da Petrobras e o limite com o município de Rio das Ostras, no extremo do bairro Imboacica.

16 - Mirante da Lagoa aterrou parte do espelho d'água e de sua área de alagamento, além de descaracterizar a APP da lagoa (RESSIGUIER, 2011, TOUGEIRO, 2008). Vivendas da Lagoa foi construído em cima da zona de alagamento e da APP da lagoa, por meio de um aterro. Fazenda Mutum, em parte, aterrou uma área de brejo da lagoa, que abastecia um de seus afluentes; Jardim Guanabara, em parte, aterrou um brejo e um braço da Lagoa de Imboacica.

17 - Assentamentos irregulares são aqueles que contrariam os regulamentos legais de gestão do território e ambiente. Já os regularizados são aqueles que apesar de contrariar esses regulamentos foram aprovados pelo poder público.

18 - O Anuário da Prefeitura Municipal de Macaé (PMM, 2012) identifica os assentamentos humanos de baixa renda na cidade de Macaé como aqueles com renda familiar média menor que dois salários mínimos. Os de alta renda possuem a média de mais de 10 salários mínimos.

19 - Trata os resíduos dos bairros Mirante da Lagoa, Jardim Guanabara, Vale dos Cristais, parte do São Marcos, Morada das Garças e Vivendas da Lagoa, todos eles assentamentos de alto poder aquisitivo.

\section{REFERÊNCIAS BIBLIOGRÁFICAS}

ANP, AGÊNCIA NACIONAL DE PETRÓLEO, GÁS E BIOCOMBUSTÍVEIS. Boletim da Produção de Petróleo e Gás Natural. Superintendência de Desenvolvimento e Produção - SDP. Rio de Janeiro, Brasil. 2014.

ANP, AGÊNCIA NACIONAL DE PETRÓLEO, GÁS E BIOCOMBUSTÍVEIS. (s.d). Disponível em: http://www.anp.gov.br/?pg=82658\&m=royalties\&t1=\&t2=royalties\&t3=\&t4=\&ar=0\&p $\mathrm{s}=1 \& 1473808913167>$ Acesso em: 10/06/2016.

ABEP, ASSOCIAÇÃO BRASILEIRA DE ESTUDOS POPULACIONAIS. Macaé: uma análise intra-urbana. In: Encontro Nacional Sobre Migrações, 5, 2007, Campinas, Anais... São Paulo, 2007. 
AZEVEDO, D. C. Caracterização da Pobreza em Macaé: uma abordagem multidimensional. 2011, 167 p. Dissertação (Programa de Pós-graduação em Política Social) - Universidade Federal Fluminense, 2011.

BARUQUI, S.S.C. A cidade formal e a cidade informal em Macaé: uma análise do crescimento habitacional da década de 90. 2004, 171 p. Dissertação (Programa de Pós-graduação em Planejamento Regional e Gestão de Cidades) - Universidade Candido Mendes, 2004.

FREITAS, L. N. ; SANTOS, K. P.; MELLO, D. S.; FERREIRA, M. I. P ; OLIVEIRA, V. P. S. Barragem e transposição do rio Macabu: conflitos gerados pelo uso da água e a integração de bacias hidrográficas no gerenciamento de recursos hídricos. In: Seminário Regional de Recursos Hídricos, 4, 2014, Campos dos Goytacazes, Anais ... Rio de Janeiro, 2014, p. 1-13.

INSTITUTO BRASILEIRO DE GEOGRAFIA E ESTATÍSTICA (IBGE). Censo demográfico de Macaé, 2010. Disponível em:< http://cidades.ibge.gov.br/xtras/perfil.php?codmun=330240>. Acesso em: 19/05/2015.

JERONYMO, C. A. L.; SILVA, E. R.; FONSECA, K. T.; FERREIRA, M. I. P. Sistemas de Informação Geográfica e a classificação de corpos hídricos: o caso de Macaé (RJ, Brasil). Caderno de Geografia. Artigo recebido para revisão em 16/03/2016 e aceito para publicação em 24/05/2016.

OHSAS, B. S. (2007). 18001: 2007. Occupational health and safety management systems. London.

OMPETRO, ORGANIZAÇÃO DOS MUNICÍPIOS PRODUTORES DE PETRÓLEO. Presidência da OMPETRO. 2016. Disponível em: < http://www.ompetro.org.br/index.php/institucional/presidencia-da-ompetro.>. Acesso em: 20/06/2016.

MACAÉ, CÂMARA MUNICIPAL. Plano de Habitação de Interesse Social: Diagnóstico das Necessidades Habitacionais e Estratégias de Ação. 2010 a. Disponível em: < www.macae.rj.gov.br/midia/uploads/PLHIS-Consolidado.pdf. Acessado em 28/07/2015.

MACAÉ, CÂMARA MUNICIPAL. Lei Complementar $n^{\circ} 141$ de 2010. 2010 b. Disponível em: <www.leismunicipais.com.br/legislacao-de-macae/1224967/leicomplementar-141-2010-macae-rj-html>. Acessado em 13/07/2015.

MACAÉ, CÂMARA MUNICIPAL. Plano Diretor do Município de Macaé. 2006 a. Disponível em: <www.macae.rj.gov.br/midia/conteudo/arquivos/1270002165.pdf>. Acessado em 30/07/2015.

MACAÉ, CÂMARA MUNICIPAL. Lei Municipal Complementar n 2.854 de 2006. Institui a Política Municipal de Habitação, cria o Fundo Municipal de Habitação e se Conselho Gestor e a Lei Municipal n. 3.278/2009 que a modifica.

MACAÉ, CÂMARA MUNICIPAL. Lei Municipal Complementar $\mathbf{n}^{\circ} 27$ de 2001. Dispõe sobre o Código Municipal de Meio Ambiente, e dá outras providências.. Disponível em: < http://www.macae.rj.gov.br/midia/conteudo/arquivos/1404928423.pdf >. Acessado em 12/07/2015.

MARCUSE, P. Enclaves sim, guetos não: a segregação e o Estado. Espaço e Debates, São Paulo, NERU, v. 24, n. 45, 2007. 
MOLISANI, M. M. ; ESTEVES, F.A. ; LACERDA, L.D. ; REZENDE, C. E. . Emissões naturais e antrópicas de nitrogênio, fósforo e metais para a bacia do rio Macaé (Macaé, RJ, Brasil) sob influência das atividades de exploração de petróleo e gás na Bacia de Campos. Química Nova (Impresso), v. 36, p. 27-33, 2013.

MOLISANI, M. M. ; COSTA, R. N. ; CUNHA, P. ; REZENDE, C. E. ; FERREIRA, M. I. P. ; ESTEVES F.A. Acute Toxicity Bioassay With the Amphipod, Grandidierella Bonnieroides S. After Exposure to Sediments From an Urban Estuary (Macaé River Estuary, RJ, Brazil). Bulletin of Environmental Contamination and Toxicology, v. 90, p. 79-84, 2013.

PAGANOTO, F. "Migrantes Ricos e Migrantes Pobres: a herança da economia do petróleo em Macaé/RJ”. In: Encontro Nacional sobre Migrações, 4, 2005, Rio de Janeiro, Anais... Rio de Janeiro, 1- 19 p.

PIQUET, R. Petróleo, royalties e região. Rio de Janeiro: Garamond, 2003, 310 p.

PMM, PREFEITURA MUNICIPAL DE MACAÉ. Anuário de Macaé. Macaé: Coordenadoria Geral do Programa Macaé Cidadão, 2012.

PMM, PREFEITURA MUNICIPAL DE MACAÉ. Série histórica de Ortofotos. Geomacaé, 2010, 2001, 1989, 1976, 1966, 1956.

RESSINGUIER, J.H.B. Atividade petrolífera e impactos no espaço urbano do município de Macaé/RJ - 1970/2010. 2011, 113 p. Dissertação (Programa de Pósgraduação em Planejamento Regional e Gestão de Cidades) - Universidade Candido Mendes, 2011.

SEA, Secretaria Estadual do Ambiente. Plano de Recursos Hídricos da Região Hidrográfica Macaé e das Ostras: relatório síntese. Rio de Janeiro: SEA, 2014. 181p.

SOFFIATI, A. Macaé em quatro tempos. In: Oficina sobre os impactos ambientais, 1, Niterói, Anais... Rio de Janeiro, 2011.

TOUGEIRO, J. V. Conflitos socioambientais motivados por ocupação de manguezais e restingas para fins de moradia no espaço urbano de Macaé/19972007. 2008, 151 p. Dissertação (Programa de Pós-Graduação em Políticas Sociais) Universidade Estadual do Norte Fluminense Darcy Ribeiro, 2008. 